\title{
ADDRESSING THE DIGITAL DIVIDE
}

\author{
Rowena Cullen \\ School of Information Management \\ Victoria University of Wellington \\ P.O.Box 600 Wellington \\ +6444635788 \\ rowena.cullen@vuw.ac.nz
}

\begin{abstract}
The phrase 'digital divide' has been applied to the gap that exists in most countries between those with ready access to the tools of information and communication technologies, and the knowledge that they provide access to, and those without such access or skills. This may be because of socio-economic factors, geographical factors, educational, attitudinal and generational factors, or it may be through physical disabilities. The paper reviews recent research concerning the digital divide in New Zealand, and the factors that alienate people from enjoying the benefits information technology and participation in the knowledge economy within New Zealand. While socio-economic factors affect use of ICTs by urban Maori and Pacific Island communities, and rural communities are affected by inadequate telecommunications infrastructure, rural Maori are even more disadvantaged. The paper examines strategies used in the US, and the UK at national and regional levels to address similar issues, strategies which can include the use of libraries to reduce the digital divide, and compares these with New Zealand initiatives in order to identify positive actions that can be taken to increase participation in the knowledge economy.
\end{abstract}

\section{INTRODUCTION}

In the global digital information age those who are either unable to access the Internet and the World Wide Web through the application of Information and Communication Technologies (ICTs) are increasingly disadvantaged in their access to information. In most Western nations government policies are being established which attempt to ensure that all citizens have the opportunity to access and effectively use ICTs in order to enable them to participate fully in the educational, social and economic

R.Cullen. Addressing the Digital Divide.LIANZA.2002 
activities and democratic processes, which make use of these technologies. The 'digital divide' has become a convenient metaphor to describe the perceived disadvantage of those who either are unable or do not choose to make use of these technologies in their daily life.

There is an equally important digital divide that we should also be concerned about, and that is the gap between the state of ICTs, and levels of access and utilisation of the Internet in developed nations and the situation in less developed countries. Dramatic differences in access to the Internet are now becoming evident as usage in the West reaches $25 \%$ of the population in most Western countries and exceeds $50 \%$ in the most advanced Internet nations- the United States and Scandinavia. And this divide goes far beyond access to the Internet for scientists, scholars and students in universities and schools in developing nations, beyond the questions of access to the Internet for ordinary citizens, and must include access to the more valuable information sources, indexes, full-text databases, and e-journals, that are not included in the freely available information on the Internet, leaving scientists and researchers in developing countries excluded from knowledge that may be vital to agricultural, social and economic development.

As the term implies the 'digital divide' focuses on the higher end of ICTs involving the electronic transfer of information using digital formats which may themselves be replaced by new technologies within the next decade. It assumes that the benefits of these technologies and access to the world of information that is contained within them is a benefit that no citizen in the twenty-first century should be without, certainly not at least in the developed world. While I am not necessarily challenging that assumption, I believe that it is timely to remember two key points about the impact of technology on human civilisation:

- Technology does not in itself solve social and economic discrepancies within societies, and can often exacerbate them. Massive growth in the use of ICTs in India, for example has had no impact at all on what has been described as "the highest concentration of poverty in the world".

- New technologies do not always replace the old. They may co-exist and in doing so enhance the range of human experience without necessarily diminishing the experience of those who do not use/utilise them, preferring older technologies to achieve the same ends.

For the majority of the world's population telephones are a technology beyond reach; food, sanitation and literacy are more urgent needs (UNESCO 1998). Bringing the Internet to an African village by the means suggested by some enthusiasts, using battery operated computers, and satellite access focuses on the wrong end of the technology spectrum, and not the end that is of most benefit to the world's poorest communities. The Internet is not in itself an education, does not teach literacy, and requires highly developed skills to access and interpret information found. A better solution for most of these communities still lies in the use of very basic technologies to promote traditional forms of education, enhance the delivery of healthcare, improve animal husbandry and crop management.

R.Cullen. Addressing the Digital Divide.LIANZA.2002 
The contribution made by the Internet to the poorest nations of the world is likely to be, at least for the foreseeable future, in other ways. These include: the sharing of global knowledge and expertise to help support their initiatives against poverty and disease; the contribution of ICTs to the developed part of the economy in each developing nation which shows the same benefits from the application of ICTs as in developed nations; better communication with trading partners through e-commerce; ability to market tourism and trade opportunities through the World Wide Web; use of low wage economy and different time zones to monitor process transactions around the Globe. A recent address of the Secretary General of the United Nations to ECOSOC outlines many ways in which poorer nations can take advantage of ICTs for social and economic growth (United Nations. ECOSOC 2000).

\section{WHO IS EXCLUDED BY THE DIGITAL DIVIDE?}

A number of research and policy papers addressing the issue of the Digital Divide identify specific groups of people as being especially disadvantaged in their uptake of ICTs. These include: people on low incomes, people with few educational qualifications or with low literacy levels, the unemployed, elderly people, people in isolated or rural areas, people with disabilities, sole parents, elderly people, women and girls. Because they are often already disadvantaged in terms of education, income and health status, and also because of their profound cultural differences from the dominant Western culture of the developed world, many indigenous peoples, and some migrant and ethnic minority groups are identified as having a very low uptake of ICTs. In the United States therefore Afro-Americans, Latinos, as well as North American Indian nations are identified as needing targeted programmes to increase their participation in the digital economy. In New Zealand, the indigenous Maori people have very specific cultural and educational needs that are the focus of government programmes aimed at 'closing the digital divide', but the large immigrant communities from the Pacific Island states also form a group of people largely excluded from the benefits of the digital revolution that the rest of the country is enjoying.

There is a developing debate as to whether this alienation from the Internet culture is primarily due to the factors listed above, or is primarily due to socio-economic disadvantage. The influential Gartner Group report 'The Digital Divide and American Society' (Gartner 2001) argues that there is a very strong correlation between socioeconomic status and participation in the digital economy that suggests cause and effect. The report is based on data gathered in the United States in February 2000 shows that while only $35 \%$ of households in lower socio-economic groups have access to the Internet, $59 \%$ of those in lower middle income groups, $73 \%$ percent of those in upper middle income groups, and $83 \%$ of those in the top income groups have access to the Internet. These disparities are presumably exacerbated by an uneven distribution of the population in the various income groups.

Gartner argue that:

While it is absolutely true that minority groups are at a distinct disadvantage when it comes to having Internet access, the reason for this is not that they are

R.Cullen. Addressing the Digital Divide.LIANZA.2002 
minorities but that they are at a socioeconomic disadvantage due to lower education levels and poorer incomes. ...

Being on the wrong side of the Digital Divide is only one symptom of being poor. Lower socio-economic groups also have far lower household incomes, less access to educational opportunities, and have far more limited job opportunities ... one of the keys to increasing the socioeconomic status of this country's poorest citizens is to grant them fair and equal access to educational and economic opportunities, and the Internet presents us with an exceptional opportunity to do just that. (Gartner 2001)

Despite these disparities in access the Gartner report found little difference in attitudes towards the importance of computing skills to a successful career and the importance of a home computer for children success in school among the various groups studied (which included blacks, rural communities, elderly people as well as the four socioeconomic groups listed above). The report possibly erroneously assumes that this result indicates that all sections of the community pace an equal value on aces to the Internet, and that it is only lack of resources that prevents people from doing so. But this assertion is untested. Further research in a wider variety of minority groups into attitudes towards and barriers preventing use of the Internet is necessary before socioeconomic reasons alone are assumed to be the major barrier to participation in the Information Age.

\section{BARRIERS TO USE OF THE INTERNET}

Among the many known barriers that Gartner assume can be subsumed under socioeconomic status are four key issues that need much more research, and which are not dependant on socioeconomic status alone. Any attempt to address the digital divide must take these potential barriers into account if it is to succeed. These four key issues are:

- Physical access to ICTs

- ICT skills and support

- Attitudes

- Content

A recent UK government report 'Keystone for the Information Age' identifies these more succinctly as the three C's: Connectivity, Content, and Competencies, attributing attitudinal barriers to lack of relevant content and lack of ICT skills (Library and Information Commission 2000). The Library and Information Association of New Zealand Aotearoa in its recently issued report 'Towards a National Information Strategy' that focuses on bringing a 'Knowledge Society' to New Zealand and encouraging participation in the Internet by all New Zealanders, uses these three concepts as a guiding principle to identify the initiatives that the government must take, and those that the library community can contribute to achieve this goal (LIANZA 2000).

Physical access

R.Cullen. Addressing the Digital Divide.LIANZA.2002 
The main barriers that are identified under physical access are lack of a robust telecommunications infrastructure with sufficient reliable band-width for Internet connections, and cost, the ability to purchase, rent, or travel to utilise without financial hardship, the necessary equipment. Affordable routine access is essential for participation in this new information age. While access is not dependent on home ownership, it can be severely constrained in the workplace; there are also constraints on the type of activity (for example, seeking advice on a benefit or housing problem) that can be carried out in the public environment of a community access centre or cyber-café.

At present land-line telephone connectivity is essential to home Internet access. Telephone access is by no means universal. For example, although the 2001 census data shows that $96 \%$ of all New Zealanders, and $89 \%$ of Maori live in dwellings with a telephone, this is not uniform across all groups. While $37 \%$ of households overall reported access to the Internet from home, this figure rises to $44 \%$ in Auckland, and falls to $25 \%$ in Gisborne and the West Coast. Up to $75 \%$ of Maori in households with incomes of less than $\$ 15,000$ in some depressed rural areas do not have access to a land-line phone at home, although some have access to a mobile telephone (Maharey and Swain 2001). Even affluent rural communities suffer from geographic isolation, low band-width, unreliable connections, and interference from agricultural equipment such as electric fences.

Rapidly developing mobile telephone technology is likely to improve Internet access to some rural communities but only those in areas which are already better served in terms of land-line services and band-with. More remote areas remain outside normal mobile telephone service, and development of mobile services in remote areas is regarded as prohibitively expensive. Satellite services, also promoted as a solution, solve only part of the problem since although they allow high band-width traffic inwards, they are unlikely to support a very high level of outwards connectivity. Other technical solutions on the horizon such as Internet access through cable TV is also likely to exclude those in the lowest socio-economic groups, the least-likely group to subscribe to cable TV systems. It must also be recognised that all these technical solutions carry costs which must either be borne by consumers, or by central government or local authorities and passed on through taxes. In countries where the telecommunications industry is privately owned, the industry is quite open about its reluctance to make a substantial investment in markets which represent a tiny percentage of the revenue stream. Technical problems are likely therefore to continue to inhibit access in rural communities for some time to come, while cost, of both the equipment and especially monthly charges remain an issue with lower socioeconomic groups in both rural and urban areas.

Physical access also includes provision of access for people with disabilities. The importance of making the Internet accessible to allow all people in the community full participation in communications systems, education, employment and other economic opportunities regardless of their physical capacity. (Maharey and Swain 2001). Indeed it is often regarded as one of the strengths of the Internet that it opens up channels of communication and access to information for people who have previously been excluded from full participation in the economic and social life of the country. Demand for access to the Internet by people with disabilities is steadily increasing and R.Cullen. Addressing the Digital Divide.LIANZA.2002 
now seen as a human rights issue. While physical disabilities inhibit keyboard use, visual impairment inhibits screen use and learning disabilities prevent large numbers of users from participating in the benefits of the Internet and its rich resources. Libraries and web developers alike, governments and the business community need educating in what are now called 'adaptive technologies' which include techniques for basic web document design that meet the 'disabled-enabled' criteria of Bobbythe web-based validation service maintained by the Centre for Applied Special Technology (CAST) ${ }^{1}$ now accepted as a world standard, and required by the United States, United Kingdom, and New Zealand and other governments for their own web sites.

\section{Lack of ICT skills and support}

Lack of ICT skills and support is another significant factor in preventing certain groups of users from using the Internet. People in the many of the disadvantaged groups listed above are often prevented from making use of ICTs because of low levels of computing and technology skills, and also, very importantly, literacy skills. Where people in business or professional occupations acquire skills as part of their employment, manual workers and the unemployed are less likely to be exposed to such opportunities. Young people who do not go onto to any form of tertiary education are equally disadvantaged. While some skills spread rapidly in communities in which they are seen to have some value (learning to drive, to repair cars, to master sporting skills, to use electronic banking facilities) computer skills may not be highly valued by these groups. The interaction of factors such as: cost, restricting access to equipment; low educational achievement; and cultural, age or gender based exclusion from literacy and computing skills counteracts against the dissemination of such skills in disadvantaged communities. Educational programmes intended to bring these skills to such groups must overcome a range of such barriers.

\section{Attitudinal barriers}

Closely aligned with lack of skill and support are cultural and behavioural attitudes towards the technology - e.g. that computers are for 'brainy' people, for males, for the young, are difficult to use or belong to a middle-class 'white' culture. Concern over the lack of security of personal information or that computers are 'unsafe' for families because of the amount of unsuitable material on the Internet. These last two were major reasons given in a recent New Zealand study of rural communities for not using the Internet (Botha 2001, 22). In developed societies the disparities between Internet access by gender are not large. A recent AC Nielson survey in New Zealand cites $53 \%$ males and $47 \%$ females having access, comparable figures for other countries are: Australia $55 \%$ males; USA 50\%; Singapore 60\%; UK 58\%. Disparities between male and female use of ICTs and therefore access to the Internet are much greater in developing countries. The involvement of women may be as low as $5 \%$ in some areas (United Nations. ECOSOC 2000). This has serious implications for women's participation in a growing global economy, and also involves a significant wastage of talent which such countries can ill afford.

Attitudinal barriers can also be culturally based. In many cultures which place high value on oral culture, personal communication and strong family and kinship

${ }^{1}$ (http://www.cast.org/bobby)

R.Cullen. Addressing the Digital Divide.LIANZA.2002 
networks, the use of computers for communication purposes will not be a high priority. Such barriers may apply to the lowest socioeconomic groups of developed nations, to strongly networked cultural minorities, indigenous groups emerging from an oral culture, and non-literate rural communities throughout the world.

\section{Content}

One significant reason why some groups choose not to access the Internet is because the content is not relevant or interesting to them. This may apply to specific groups in society, such as the elderly, or women, but more significantly again, to cultural or ethnic groups outside the predominantly Western culture of the Internet. In many societies digitisation of heritage collections is proceeding at a considerable pace and these often include rare and highly valued records of indigenous peoples - raising complex issues of ownership and access. But equally important is contemporary content that is relevant to these communities. The National Congress of American Indians lists Content and Sovereignty as key issues that along with Access, Economic investment and Education are essential to the development of the web as a resource for economic development, and for use in Native American Schools as a teaching/learning resource (NCAI, 2001). Specific interests of Maori communities in New Zealand centre on land, the language and genealogy, and several key reports recently have recommended government initiatives to help Maori communities develop content on these topics, to provide access to Maori land records, and to create more Maori content on the Internet including material in the Maori language (LIANZA 2001; Information Policy Summit 2001)

\section{THE GLOBAL DIGITAL DIVIDE}

What figures are available for national rates of access to the Internet (gleaned from a wide variety of sources) indicate a huge disparity between nations. Patterns of use can easily be seen to reflect cultures, the balance between rural and urban economies, and levels of literacy.

Figure I. Sample statistics on world connectivity

\begin{tabular}{|l|l|l|l|}
\hline Country & Date & $\begin{array}{l}\text { Number } \\
\text { online }\end{array}$ & $\begin{array}{l}\text { \%age of } \\
\text { population }\end{array}$ \\
\hline Albania & Dec 2000 & 12,000 & 0.34 \\
\hline Denmark & May 2002 & 3.23 mill & 60.38 \\
\hline France & May 2002 & 16.97 mill & 28.39 \\
\hline Germany & May 2002 & 30.2 mill & 36.37 \\
\hline UK & May 2002 & 34 mill & 56.88 \\
\hline USA & April 2002 & 165.75 & 59.1 \\
\hline
\end{tabular}

Figures are derived from the Nua web site(http://www.nua.ie). Figures include all users, adults and children, who have accessed the Internet in the past three months, or where this figure is not available, in the past six months or earlier. The figures include

R.Cullen. Addressing the Digital Divide.LIANZA.2002 
all people who have accessed the Internet and is not specific to Internet account holders. Where only data on account holders is available this has been multiplied by a factor of three.

Focusing on our own region, the following data can be derived from the NUA tables.

\section{Figure II. Asia/Oceania}

\begin{tabular}{|l|l|l|l|}
\hline Country & Date & Number online & \%age of population \\
\hline Australia & Feb 2002 & 10.63 mill & 54.38 \\
\hline Bangladesh & Dec 2001 & 150,000 & 0.11 \\
\hline China & May 2002 & 37.95 mill & 2.92 \\
\hline Hong Kong & April 2002 & 4.35 mill & 59.58 \\
\hline Japan & April 2002 & 51.34 mill & 40.43 \\
\hline Malaysia & Dec 2001 & 5.7 mill & 25.15 \\
\hline New Zealand & April 2002 & mill & 51.29 \\
\hline
\end{tabular}

With the Internet population in Asia growing at a rate estimated to be as much as $45 \%$ per year Asia is expected account for approximately 25\% of all Internet users in the world by 2003 . With this rate of growth, it seems reasonable to assume that nations with what has been described as 'moderate levels of development' will have a chance to catch up with post-industrial societies in terms of education, access to information and to some extent economic development, where a new level playing field allows them to take advantage of e-commerce, and Internet tourism promotion. Developing societies look well poised to take advantage of the technology to enhance their participation in the global economy (Norris, 2000), although within such societies disparities between affluent urban youth, and illiterate rural communities are exacerbated rather than alleviated by such technology 'gaps'. In the undeveloped world the situation is even more alarming. The United Nations Human Development Report for 1999 (UNDP, 1999) predicted that gains in productivity due to the new technology could widen the differences in economic growth between affluent and poorer nation as unable to invest in the infrastructure, and training needed to support the information society.

A high level United Nations sponsored meeting of government ministers and leaders in technology from developed and developing nations around the world met in New York in April 2000 to discuss the role of ICT programmes in development, to share experiences in both the wealthiest and poorest nations and to look for ways in which R.Cullen. Addressing the Digital Divide.LIANZA.2002 
the poorer nations could extract early and tangible benefits from ICT, and globalization rather than, as they put it 'watch globalization extract benefits from them.' The panel called on all parties to unite to provide access to the Internet for the world's population presently without it by the end of 2004, and proposed as action points for reaching this goal that the UN should proclaim the universal right of access to ICTs such as the Internet as an important new component of the United Nations principles and conventions on human rights. The UN has so far declined to do so, but the Secretary General's statement subsequent to this report acknowledges the Internet as having a significant role to play in achieving human rights for all people.

The goal of universal access to the Internet was to be achieved by the establishment of an ICT Task force, an establishment fund of \$500 million dollars to which the private sector and foundations would also be invited to contribute, and the writing off of one percent of debt for each developing country that would allocate the equivalent to ICT development. The UN was to arrange for international financing for ICT development for countries that met certain targets in their carbon-fixing activities.

Twelve national reports focus on the very real benefits, and the substantial growth in the sector that planned development of ICTs have brought to a number of countries in Europe, South America and Africa. One notable development is the Small Island Developing States Network which links 42 Island nations in the Caribbean, Indian, Atlantic and Pacific Oceans, giving them both vital links with the wider world from which they have traditionally been very isolated, the possibility of joint educational, health and business initiatives as well as some combined clout in their attempts to break some of the monopolistic telecommunications practices which keep connectivity charges prohibitively high ${ }^{2}$. Such monopolistic practices have generally been outlawed in developed nations. The irony of globalisation is that the smaller and less developed the nation, the lower the average national income, the higher telecommunications charges seem to be.

\section{SOLUTIONS}

\section{The global digital divide}

There are no quick or easy solutions to the problem of the digital divide, either within nations or between nations. The disadvantaged in both rich and poor nations have too little cash to attract the attention of multi-national computer and telecom giants for long, and the big bucks are likely to be made in higher band-width and new technologies. However, in the plethora of UN, government and commercial reports concerning the digital divide there are a range of solutions proposed, and some of them specifically address the barriers to Internet use which we noted earlier: lack of physical access to ICTs; lack of ICT skills and support; negative attitudes; lack of relevant content.

In his report to ECOSOC the Secretary General of the UN focused on some key points that need to be addressed in order to assist developing nations increase their adoption of the Internet in their own communities and enhance their participation in

2 (http://www.sidsnet.org)

R.Cullen. Addressing the Digital Divide.LIANZA.2002 
the Global economy. Many of these involve international development initiatives and collaborative efforts between governments, donor organisations, and NGOs. He calls for a more effective transfer of knowledge from the rich Northern hemisphere to the South and notes the increasing number of scientific and research publications appearing on the World Wide Web, a development which brings more benefits to the developing South than to researchers in the North who would have other forms of access. The importance of information flows South-South, and South-North should also be recognised and fostered, so that expertise in successful planning and implementation of ICT development projects can be shared and resources are not wasted.

The Secretary General's report notes that lack of physical telecommunications infrastructure is not the key problem in many parts of the developing world where mobile technology is already well developed. Internet access for mobile telephone owners is predicted to reach nearly 1 billion people by 2003, although as we noted earlier this does not guarantee access in areas remote from normal transmission services. However, mobile technology is developing rapidly and these problems may well be resolved in the next few years. A more intractable issue is the fact that $98 \%$ of Internet Protocol bandwidth globally connects to and from North America. The US operates as the hub of Internet traffic and countries must make payments for traffic exchange and connectivity to US telecommunications carriers. Not only does this require foreign exchange payments in prohibitively high US dollars which developing countries can barely afford, it reverses the accounting system for telephone traffic where the cash flow is from the developed to the developing world. As more and more users transfer land telephone systems to the Internet, not only do developing nations lose cash income, they must pay increased charges for this connectivity. Careful renegotiation of existing global telecommunications agreements and a restructuring of the World Wide Web, a difficult task when the Web has no formal governance structure, will be needed to address these issues.

At the country level one of the most important issues raised in the UN report is the success that has been achieved in developing local community access centres, whether these are established in existing community centres, schools, meeting houses etc, or brought to the community in mobile units, not unlike mobile libraries. Indeed in some regions they could easily be combined with these. This involves a paradigm shift from the concept of individual connectivity to community connectivity, contrary to the thrust of the Gartner Report which insists on domestic access to ensure maximum advantage of the technology. However, it has to be recognised that for much of the world, individual connectivity is an unachievable, and not necessarily a relevant goal, and that therefore models of community connectivity need to be seriously explored. The Secretary General's report refers to an example cited in the report of the expert panel, of mobile Internet units in Cost Rica, known as LINCOS (Little Intelligent Communities) which are multipurpose multimedia mobile units housed in cargo containers and powered by a generator. LINCOS offer Internet access, e-mail, and training in ICT as well as banking facilities, telemedicine, soil testing and FM radio and TV in a small theatrette. Cargo containers have been used for telephone centres in Africa for some years, and container based Multipurpose Community Telecentres are being set up in several African states on a trial basis as part of an African Information

R.Cullen. Addressing the Digital Divide.LIANZA.2002 
Society Initiative ${ }^{3}$. This is perhaps a solution for the poorest communities across Africa, which has the lowest levels of connectivity in the world, but only where existing literacy levels are adequate for advantage to be taken of the rich resource being offered.

While content development is not often seen as a primary factor in Internet uptake, inappropriate or inaccessible content continues to be a major deterrent. The use of English as the lingua franca of the Internet is far more inhibiting than English speakers realise. However, despite its dominance in cyberspace, English is in fact declining in terms of the number of speakers, as cultures using other languages grow more rapidly. The development of local content and more widespread use of automatic translation systems are necessary to address this issue. The example of China is often given, and the fact that only when the Internet in China was developed in Chinese characters did the $95 \%$ of the population who do not read English show any interest in connecting to the Internet. Usage multiplied immediately 10 -fold and continues to grow at the same rate. The same rapid expansion was experienced in Russia after the introduction of cyrillic letters to the Web interface. If we wish to accelerate the adoption of the Internet as a new technology innovation, relevant content in the vernacular, or language of each community is a key issue in persuading users of the relative advantage of the technology, and reducing the complexity involved in its use.

\section{Solutions within developed nations}

Addressing the problem within one of the most wired communities on the globe, the Clinton Administration proposed a 7-point scheme to eliminate the digital divide within America. It included:

- tax incentives to encourage private sector donation of computers, and sponsorship of community technology centres and training centres;

- funds to train all new teachers in the effective use of IT;

- funding for community technology centres in low-income rural and urban areas;

- public/private partnership to expand home access to the Internet for low income families;

- promotion of innovative use of technology for under-served communities

- subsidies to accelerate private sector extensions of broad-band networks in underserved communities;

- funding to help prepare Native Americans for careers in IT.

Not all of these initiatives are suitable for other communities, although they are carefully targeted at what are perceived as the key problems in the US. Among them are some key points - the solutions at least for developed nations attempting to reach the disadvantaged sectors of the community and assist indigenous peoples become involved in the ICT economy. They address two of the four basic issues affecting uptake of the new technologies, focusing primarily on physical access, i.e. supplying the hardware and enhancing networks and infrastructure; and ICT skills training in both schools and communities. Certain benefits may flow on from addressing these two fundamental tasks. Once the skills and access to the technology are in place

${ }^{3}$ (www.bellanet.org/partners/aisi/telepro2.htm) R.Cullen. Addressing the Digital Divide.LIANZA.2002 
perhaps it is easier to change attitudes and encourage the development of relevant content, created by the groups who find existing content irrelevant or unsympathetic. This has started to happen in North American Indian communities where tribes are building on their newly acquired skills to develop content for each Indian nation. The same development is taking place in New Zealand where a Maori Internet Society has been formed to promote Maori involvement in the Internet, and a large number of Maori tribes or iwi have their own sites. LIANZA is strongly promoting content as an issue to the New Zealand government in its National Information Strategy, not only because local content may attract more users from the groups not currently on-line, but because most content on the Internet is currently created in the United States and United Kingdom, and because it is essential that we continue to create our own local material for domestic use as well as to communicate with the world. Recent initiatives, such as the online Encylopedia New Zealand recently launched by the ministry for Culture and Heritage ${ }^{4}$, or its companion web site NZHistory . Net $^{5}$ are starting to produce some of this kind of material.

The Doczi report, prepared for the then Ministry of Commerce (Doczi 2000) summarizes research in NZ and elsewhere, and lists potential solutions in other countries that might be applicable here. These include the provision of community access sites for training/use of ICT, subsidising ICT training for those on low incomes, and the schemes for promoting the development of national online content. The Doczi report also considers the benefit of:

- tax incentives to businesses supplying hardware and training;

- increased investment in high speed connectivity;

- improving access to govt online services;

- partnerships with industry, communities, local government;

- increasing competition and reducing costs;

- making spectrum available for new services.

Community access centres can be based in schools, churches, job training centres, or community centres, or in New Zealand on marae (Botha, 2001). A different, but very successful community training model, SeniorNet, has also been developed in New Zealand. This is a loose network of local societies each of which is formed in its own community and incorporated as a non-profit-making society. Members receive initial training and then pass on skills to other members who pay minimal fees for training and access. Most SeniorNet members eventually acquire and rely on their own Internet access at home, and use the society for training purposes only.

The Botha report, prepared for the Ministry of Agriculture, looked at several other community access models analysing the potential of each to address the problems of rural communities in New Zealand. The models identified were: the social service model; the free market model; the extension model (based on existing community services in schools and libraries); the SeniorNet model; and the mobile model (Botha, 2001, 25-26). Several examples of free market model community access programmes were identified in both urban and rural areas across North America and Europe, known either as telecentres or telecottages. These are usually based on the concept of

${ }^{4}$ http://www.mch.govt.nz/ref/enz/index.html

${ }^{5}$ http://www.mch.govt.nz/History/nzhist.html

R.Cullen. Addressing the Digital Divide.LIANZA.2002 
a salaried manager, offering access and training within the community on a semicommercial self-sustaining basis. The Botha report's analysis of the success and failure of a large number of initiatives around the world in sustaining such community access centres reaches the following conclusions:

- financially self-sustaining access centres seem to be unworkable in rural areasthe failure rate in most parts of the world is high;

- coordinating teams promoting such ventures nationally should ideally be independent of any one government agency but should act as a catalyst between government agencies, business and the community;

- community access centres need to be community driven, have high community participation, and focus on community needs rather than the technology;

- training in valued ICT and other skills that people value are essential for community involvement;

- clear incentives are required to foster the development of such centres, and cooperation between community groups and business and schools.

(Botha 2001, 48)

Examining these well-researched conclusions it seems that we can deduce that unless usage of community access centres is sufficiently high and the products offered are worth consumers paying a commercial fee for, we are back in the situation that those with the most need can lest afford to pay. Subsidies will continue to be necessary to bridge the digital divide, and relevance to community needs will drive uptake.

Solutions to the problem of broad-band access throughout the community is highly dependant on the telecommunications structure of each country. Deregulation of the industry is perceived to be the best solution, but competition will not necessarily bring higher band-widths to more remote areas. For example, in New Zealand Telecom claims that it can deliver adequate band-width (14.4kbs or better ) to $95 \%$ of the country and that it cannot afford to upgrade its networks to cater for the remaining highly vocal $5 \%$ - a total of 47,000 consumers. Its overseas shareholders demand a higher level of profit than this. Competition alone will not resolve this question, legislation, pressure and some subsidy may be necessary and rural communities are already exploring building their own telecommunications networks to get around the problem. The introduction of Telecommunications Service Obligations, whereby social objectives can be mandated for performance by telecommunications providers may see increased pressure from government on Telecom and its competitors to deliver a universal service to remote users. This legislation has already been used to require Telecom and its competitors to provide service to the hearing disabled. An alternative solution is evident in Project PROBE (Ministry of Education 2002) which has been developed to roll out broadband to all schools and communities that do not have access to broadband communications and to encourage competition in broadband telecommunications outside the metropolitan centres. The project is currently seeking the submission of RFPs for all regions, including those where locally based initiatives are already underway, as in Southland and Northland.

R.Cullen. Addressing the Digital Divide.LIANZA.2002 
A further initiative, the government's "Connecting Communities" strategy, driven by the Department of Labour's Community Employment Group, summarises the endeavours of several government agencies to provide solutions to the Digital Divide, and recommends greater coordination between such agencies, the development of infrastructure and networks, research and evaluation programmes, training programmes, and the development of partnerships with community groups. (Community Employment Group 2002). A strength of the proposal is its recognition of the role of libraries in developing these infrastructures and skills, and the importance of the proposed Library and Information Commission in the new National Library Bill as a part of the needed co-ordination. The establishment of a small unit in the Community Employment groups, dedicated to reducing the Digital Divide, similar to the State Services Commission's E-Government Unit should ensure that initiatives are not lost between competing government agencies, as threatened to happen with the question of access to electronic government information. .

\section{THE ROLE OF LIBRARIES IN CLOSING THE DIGITAL DIVIDE}

Libraries, with their commitment to freedom of access to information, and promotion of life-long learning have an important role to play in closing the digital divide. They have been the force behind many initiatives to increase reading, literacy and access to information in the past, from the very foundation of public libraries as self-education resources for workers to the mobile libraries found in some form in all library cultures over the past century, to adult literacy and community education programmes. Libraries need, as many already do, to take an active part in the promotion of information literacy, including ICT and Internet skills, in their own communities, pressing for its inclusion in the school curriculum, and in teacher training. They also have a key role to play in promoting use of and knowledge of disabled-enabled web technology, and promoting adaptive disabled-enabled technology on their own web sites.

Public libraries in particular, and this includes national and provincial libraries in countries where these play a similar role in the provision of community services have a key role to play as a community access point. Many public libraries already play a significant role in the community, and have excellent knowledge of community needs. This is recognised in the government's "Connecting communities" strategy This can be harnessed and extended to ascertain the best ways of increasing access to ICTs within the community. It may means some action-based research to increase knowledge of needs and preferences. And the answers may require some changes. They may mean revisiting Internet access charges, allowing community groups to use the library during evening hours for community access programmes. seeking out community groups and social agencies with which to form strategic alliances, and persuading local councillors that investment in community access programmes to increase ICT and Internet use brings economic benefit to a community in a very cost effective manner.

A very effective model to promote such initiatives has been has been proposed in the United Kingdom with the People's Network concept which offers contestable funding R.Cullen. Addressing the Digital Divide.LIANZA.2002 
for libraries ("our street-corner universities") developing initiatives for community access, especially staff training, content creation, and the development of Lifelong Learning Centres. ${ }^{6}$ In rural communities, the regional library system can be a major promoter of community access programmes, offering premises and well researched and informed analysis of the critical success factors in such ventures, including those outlined above.

New Zealand libraries also need to become involved in community initiatives, and assert their place in strategies such as "Connecting communities" and Project PROBE. LIANZA's National Information Strategy already goes as long way towards this, focusing on

- Identifying information literacy as part of key literacies needed in $21^{\text {st }}$ century;

- The role of libraries, in partnership with government for training and access;

- Partnership with Maori to increase use of te reo as a means of promoting literacy, Maori information literacy, and content.

Working in cooperation with the government and the National Library, LIANZA's National Information Strategy is an appropriate framework to give libraries a key role in the knowledge economy.

\section{REFERENCES}

Botha, N, Small, B and P Crutchley (2001) Addressing the rural digital divide in New Zealand. Client report for MAF, March 2001. Wellington: Ministry of Agriculture.

Community Employment Group, Department of Labour. 2002. Connecting communities: a strategy for government support of community access to information and communications technology. Wellington: Department of Labour.

Doczi, Marianne. 2001. Information and Communication Technologies and Social and Economic Inclusion: Addressing the social and economic implications of limited e-literacy and access to information and communication technologies. Wellington: Ministry of Economic Development. http://www.med.govt.nz/pbt/infotech/ictinclusion/index.html .[Accessed 31/9/02]

Gartner Group (2000). The Digital Divide and American Society

Information Policy Summit. 2000. School of Communications and Information Management, Victoria University of Wellington.

Library and Information Commission. 2000. Keystone for the Information Age: a national information policy for the $U K$ (http://www.lic.gov.uk/publications/other/keystonereport.html)

Library and Information Association of New Zealand Aotearoa (2001) Towards a National Information Policy. Wellington: LIANZA, http://www.lianza.org.nz/nis.htm [accessed 15/05/01]

Maharey, S and Paul Swain. 2001. Closing the Digital Divide -What do we know about the digital divide in New Zealand?. http://www.executive.govt.nz/minister/maharey/divide/01-01.htm [accessed 28/04/01]

${ }^{6}$ (http://www.peoplesnetwork.gov.uk).

R.Cullen. Addressing the Digital Divide.LIANZA.2002 
Mates, Barbara T. Adaptive Technology for the Internet: making electronic resources accessible to all. Chicago, Ill: American Library Association, 2000.

National Congress of American Indians (2001) American Indians and the Digital Divide. http://www.ncai.org/indianissues/DigitalDivide [accessed 28/04/01]

New Zealand. Ministry of Education. 2002. Project PROBE (Provincial Broadband Extension.

http://www.minedu.govt.nz/index.cfm?layout=document\&documentid=7328. [Accessed 29.11.02]

Norris, Pippa. The World-wide Digital Divide: information poverty, the Internet, and Development. Presented at the Annual Meeting of the Political Studies Association of the United Kingdom. London School of Economics and Political Science, 10-13 April, 2000. http://www.pippanorris.com/[accessed 15/05/01]

Nua Ltd. (2001) Nua Internet surveys. http://www.nua.ie [accessed 15/05/01]

UNDP. 1999. Human development report 1999. New York: UNDP/Oxford.

UNESCO 1998. World Communications Report: the media and challenges of the new technologies. Paris: UNESCO.

United Nations. 2000 Report of the meeting of a high level panel of experts on information and communication technology, New York, 17-20 April 2000. . New York: United Nations.

United Nations. ECOSOC. 2000. Development and international cooperation in the twenty first century: the role of information technology in the context of a knowledge-based global economy. A report of the Secretary General 16 May 2000. ECOSOC 2000/52. New York: United Nations.

R.Cullen. Addressing the Digital Divide.LIANZA.2002 